\title{
Os Efeitos de Contexto nas Representações Sociais sobre o Corpo
}

\author{
Ana Maria Justo ${ }^{1}$ \\ Brigido Vizeu Camargo \\ Catarina Durante Bergue Alves \\ Universidade Federal de Santa Catarina
}

\begin{abstract}
RESUMO - Objetivou-se compreender o papel do contexto nas representações sociais (RS) sobre o corpo, num estudo quaseexperimental, com 79 participantes. O contexto foi variável independente, sexo e geração variáveis controle e RS sobre o corpo a variável dependente. Os participantes assistiram a vídeos (manipulação do contexto), realizou-se grupo-focal e aplicou-se questionário. A análise envolveu estatística descritiva, testes de associação e multivariados. Resultados indicam que a saúde estrutura a RS, mas junto aos demais elementos emergem RS diferentes em função do contexto. No contexto de saúde, o corpo é veículo da existência e cuidado. No contexto de beleza é um objeto social, sujeito a padrões. Aponta-se para a dinâmica do pensamento social, que traz implicações teóricas e metodológicas aos estudos de RS.
\end{abstract}

Palavras-chave: representações sociais, corpo, contexto

\section{Context Effects on Social Representations of the Body}

\begin{abstract}
This study sought to comprehend the role context has on social representations (SR) of the body, using a semi-experimental design, with 79 participants, with context as the independent variable, SR as the dependent variable and sex and generation as control variables. Participants watched videos (manipulating context), followed by a focal group and a questionnaire. The data were analyzed using descriptive statistics and multivariate tests. Results indicate that health structures SR, however, together with other elements different SR emerge due to the context. In the health context, the body is a vehicle of existence and care. In the beauty context, the body appears as a social object, subject to aesthetic standards. These findings point to a dynamics of social thought, with theoretical and methodological implications for the studies on SR.
\end{abstract}

Keywords: social representations, body, context

O corpo pode ser definido como um organismo natural, um conjunto de órgãos que permite as funções necessárias à vida (Durozoi, 1996), mas caracteriza-se também pelas representações individuais e sociais a ele associadas. Não é apenas individual, nem estritamente social, mas resultado de uma construção simbólica, segundo percepções e representações individuais e coletivas (Andrieu, 2006), as quais se modificam e refletem o momento histórico e social de um grupo (Ory, 2006). Tem a particularidade de ser ao mesmo tempo privado e social, objeto de uma experiência pessoal imediata e do pensamento social, regido por sistemas prescritivos, evidenciados nas cenas sociais (Jodelet, Ohana, Bessis-Moñino, \& Dannenmuller, 1982), o que o torna um relevante objeto de estudo para a psicologia social - em especial à teoria das representações sociais - TRS (Jodelet, 1984).

O estudo do corpo a partir da TRS apresenta a possibilidade de integração das dimensões privadas àquelas socialmente compartilhadas e que refletem em modos de se relacionar, tanto com o próprio corpo com corpo dos outros (Jodelet, 1994). As representações sociais (RS), de acordo com a autora, assumem um papel importante na elaboração

1 Endereço para correspondência: Laboratório de Psicologia Social da Comunicação e Cognição, LACCOS, Universidade Federal de Santa Catarina, Centro de Filosofia e Ciências Humanas, Departamento de Psicologia, Campus Universitário Trindade, Bloco C, $2^{\circ}$ piso, Florianópolis, SC, Brasil, CEP: 88.040-900,E-mail: anamjusto@ yahoo.com.br de maneiras coletivas de ver e viver o corpo, difundindo modelos de pensamento e de comportamento a ele relacionados.

Moscovici (1961/1976) considera que as RS são produzidas coletivamente e contribuem para processos de formação de condutas e de orientação das comunicações sociais. E a TRS, de acordo com Vala (2006), aprofunda-se sobre os processos por meio dos quais os indivíduos em interação social constroem explicações acerca dos objetos sociais. As RS são processos dinâmicos (Moscovici, 1961/1976) e têm a comunicação como sua condição de existência (Jodelet, 2001), destacando seu caráter social, compartilhado, que reflete as normas e valores de um grupo. As RS servem ainda como um guia para a ação (Abric, 1998) orientando indivíduos e grupos em suas práticas.

Os estudos já realizados sobre as RS do corpo têm demonstrado que este possui um papel importante nas relações sociais, associado ao poder de sedução e de influenciar nas relações pessoais em diversas situações (Camargo, Goetz, \& Barbará, 2005; Gamboa, Tura, \& Bursztyn, 2009; Jodelet, 1994; Jodelet, Ohana, Bessis-Moñino, \& Dannenmuller, 1982; Justo, Camargo, Moreira, \& Goetz, 2009). O corpo está associado a padrões de beleza que exigem medidas precisas (Camargo et al., 2005), e é essencial ao formar a impressão sobre alguém. Embora a beleza seja considerada como uma qualidade de caráter subjetivo e de difícil definição (Le Pape, 2006), os estudos de RS a associam aos padrões e às tecnologias que favorecem o embelezamento do corpo - desde cosméticos tradicionais, até as técnicas invasivas - que são 
difundidas e tornam-se mais acessíveis à população (Camargoet al., 2005; Goetz, Camargo, Bertoldo, \& Justo, 2008).

Ao mesmo tempo em que se apresentam inúmeros modos de cuidar da beleza do corpo, vive-se um momento de constantes campanhas pela saúde, cuidados com o corpo que possibilitem seu bom funcionamento. $\mathrm{O}$ aumento da longevidade das pessoas, enfatizando o olhar mais atento à saúde, aliada à qualidade de vida, se apresenta como outro enfoque importante para se pensar o corpo e os cuidados relativos a ele. Nesse âmbito Azevedo e Ramos (2006), Hillesheim, Somavilla, Lara e Dhein (2005), Hoga e Reberte (2006) e Natansohn (2005) evidenciam o corpo como um objeto da saúde, como um objeto terapeutizado, medicalizado, manipulado por profissionais da área.

Nos estudos acerca da estrutura da representação social destacam-se os elementos saúde e beleza, que têm se mostrado centrais ao pensamento social a respeito do corpo (Gamboaet al., 2009; Justo et al., 2009). Tais elementos, os quais organizam as RS sobre o corpo, podem repercutir em práticas distintas, mas também têm uma zona de intersecção, visto que os padrões do que é ser saudável e o que é ser belo se aproximam. Desse modo, evidencia-se a importância de verificar quais são as RS sobre o corpo que emergem em função do contexto onde ele está inserido.

Teóricos das representações sociais já apontaram a importância de se considerar o contexto ao estudar as RS. O contexto abrangeria os fatores contingentes a situações de interação, fazendo com que uma mesma representação manifeste-se de modo diferenciado (Flament \& Rouquette, 2003), ou seja, refere-se ao contexto cognitivo em que o indivíduo interage com suas representações segundo a pertinência situacional (Camargo, 2006). Uma vez que o corpo pode estar inserido em diferentes contextos no cotidiano, de acordo com a situação social, diferentes elementos da representação poderiam ser ativados quando há ênfase na saúde ou na beleza corporal.

Doise (2011) explicita a existência de um metassistema, constituído de regulações sociais, as quais são normativas e controlam as operações cognitivas, sendo que, de acordo com a ocasião, os indivíduos podem fazer intervir diferentes metassistemas. Desse modo, o funcionamento cognitivo é mediado pelos sistemas normativos que imperam em cada situação. De acordo com Souza-Filho e Beldarrain-Durandegui (2009), situações ou contextos específicos podem permitir uma maior liberdade aos indivíduos em relação ao controle social. Doise, Clemence e Lorenzi-Cioldi (1992), Rouquette (1994) e Wagner (1998), apontam para a importância de se estudar a origem das RS no contexto de comunicação, onde elas são constituídas e envolvendo o contexto no qual elas se expressam e ganham vida.

Ao tratar dos efeitos de contexto nas RS, Abric e Guimelli (1998) afirmam que este fenômeno se diferencia conforme o tipo de contexto que está em questão. Distingue-se o contexto global, referente à localização social e ideológica do indivíduo e seu meio; e o contexto imediato, referente a situações específicas. Supõe-se que o efeito do contexto global seja mais influente sobre a RS, entretanto o presente estudo objetiva verificar as implicações do contexto imediato nas RS sobre o corpo.
Além das implicações do contexto, o presente estudo pretende realizar investigações acerca do papel do grupo geracional nas RS sobre o corpo. Uma geração é definida como um conjunto de indivíduos com aproximadamente a mesma idade e mesmas experiências, que são contemporâneos, de modo que a geração permite explicar comportamentos dos seus membros a partir das condições que são peculiares a sua época (Bacon, 1986). Somada à questão histórica e social, a comparação de dois grupos geracionais implica também em considerar que estes dois grupos encontram-se em distintas etapas do desenvolvimento (Papaléo-Netto, 2002). Nesse sentido, hipotetiza-se que pessoas nascidas em períodos distintos, e que atualmente encontram-se em etapas diferentes do seu ciclo de vida poderiam apresentar diferentes teorias de senso comum sobre o corpo. Assim, por meio do controle das variáveis "grupo geracional" e "sexo"; e da manipulação do contexto onde as representações sociais sobre o corpo serão enunciadas, esta pesquisa pretende investigar as implicações do contexto de inserção nas RS sobre o corpo em homens e mulheres de diferentes grupos geracionais.

\section{Método}

Trata-se de um estudo descritivo e explicativo (Richardson, Peres, Wanderley, Correia \& Peres, 2008). A pesquisa tem delineamento experimental (Kerlinger, 1980); e caracteriza-se como um quase-experimento, pois não foi utilizada amostragem aleatóriacom plenos controles dos estímulos, oque é necessário para definir um experimento autêntico (Campbell \& Stanley, 1979; Günther, 2011). Houve a manipulação da variável independente contexto de inserção $(C)$, com as modalidades contexto de beleza $(\mathrm{Cb})$ ou contexto de saúde (Cs) e o controle das variáveis faixa etária $(F)$, com as modalidades jovem ( $F j)$ e adulto $(F a)$ e da variável sexo, com as modalidades homens $(H)$ e mulheres $(M)$. A variável dependente é a RS sobre o corpo, a qual foi identificada a partir de material verbal proveniente de teste de evocações livres e discussões em grupos-focais. Configuram-se seis condições experimentais, conforme o contexto em que a RS é ativada, a faixa etária e o sexo dos participantes, tratando-se de um delineamento 2X2X 2 (Contexto [beleza, saúde] $\mathrm{X}$ Geração [jovem, adulto] X Sexo [homens, mulheres]), onde a primeira foi manipulada e as duas últimas variáveis foram controladas.

\section{Participantes}

Participaram deste estudo 79 pessoas distribuídas de modo equivalente entre homens e mulheres, bem como entre jovens e adultos. As sessões experimentais foram realizadas em grupos de cinco participantes cada uma. Dessa forma, realizaram-se oito sessões para cada modalidade de contexto.

Todos os participantes integram a comunidade universitária da UFSC (Universidade Federal de Santa Catarina) e compuseram dois subgrupos: participantes jovens e adultos. O grupo de jovens foi composto por 20 homens e $20 \mathrm{mu}-$ lheres, com idade entre 18 e 25 anos $(M=21$ anos, $D P=2$ anos e 3 meses), estudantes de graduação ou pós-graduação 
da UFSC. O grupo de adultos foi composto por 20 homens e 19 mulheres, com idade entre 41 e 58 anos $(M=54$ anos e meio, $D P=4$ anos), sendo todos eles servidores técnicos da UFSC. Estatisticamente, o intervalo de tempo entre duas gerações adotado pelos cientistas sociais é o período de 30 anos (Bacon, 1986). Desse modo, a diferença média entre os dois grupos é equivalente à diferença de idade entre pais e filhos, repercutindo na diferença de uma geração entre os grupos comparados.

\section{Instrumentos}

Na realização deste estudo foram utilizados os seguintes instrumentos:

\section{Roteiro para grupo-focal.}

Consiste em perguntas realizadas pelo experimentador, para possibilitar um debate no grupo sobre o assunto apresentado no audiovisual. O debate visava salientar os contextos "saúde" ou "beleza" para cada grupo experimental.

\section{Questionário.}

Para a coleta dos dados foi utilizado um questionário auto-administrado pelos participantes durante cada sessão experimental, composto por: a) diagnóstico da RS sobre o corpo a partir de um teste de evocações livres, que consistiu em pedir que os indivíduos produzissem individualmente cinco palavras ou expressões que lhe viessem à mente (Oliveira, Marques, Gomes,\& Teixeira, 2005) a partir do termo indutor "corpo"; b) tarefa para mensurar atitude em relação ao corpo; c) perguntas acerca da satisfação corporal; d) peso e altura auto-atribuídos (para cálculo de IMC); e) caracterização social da amostra.

\section{Materiais e Procedimentos}

Para manipulação do contexto foram utilizadas duas apresentações de vídeo, sendo que uma enfatiza o contexto de saúde e outra enfatiza o contexto de beleza, e ambas fazem relações com o objeto de estudo: o corpo humano. Ambas têm duração de cinco minutos e trinta segundos e foram criadas pelos pesquisadores para a execução do estudo. O roteiro dos vídeos desenvolvidos baseia-se no resultado de pesquisas anteriores (Camargo \& Justo, 2008; Justo et al. 2009). A partir diagnóstico dos elementos e da estrutura da RS sobre o corpo, organizou-se um roteiro para cada um dos vídeos, os quais são equivalentes em termos de recursos utilizados (mistura de elementos de vídeo, fotos e narração de textos) e estrutura (com quantidade similar de conteúdos apresentados). As imagens dos vídeos apresentam o corpo de pessoas de diferentes idades, etnias e classes sociais. Após a edição de imagens e músicas que compunham os audiovisuais, foi elaborada uma narração para cada um deles. Esta narração, equivalente entre ambos os vídeos, teve o objetivo de associar as imagens que eram apresentadas com o tema da pesquisa, para que os participantes mantivessem o corpo como foco enquanto assistiam ao audiovisual.
Após a edição dos audiovisuais, os mesmos foram submetidos a um processo de validação, com a análise de juízes (oito profissionais da área de saúde e de estética corporal). Individualmente, os juízes assistiam a ambos os audiovisuais e em seguida participavam de uma pequena entrevista estruturada a respeito dos mesmos. Perguntava-se eram identificadas diferenças entre os vídeos e quais seriam estas. Ao fim solicitava-se que o juiz apontasse o vídeo mais relacionado à sua área de trabalho. A concordância entre os juízes foi de $100 \%$. Desse modo, foi assegurada a validade dos audiovisuais para realizar a manipulação de contexto desejada.

Os procedimentos para a realização da pesquisa consistiram em recrutar os participantes e agendar a sessões, executar os experimentos, realizar as transcrições dos grupos focais e tabular dos dados. Cada etapa será descrita separadamente.

\section{Recrutamento dos participantes e agendamento das sessões.}

Após identificar os voluntários a participarem do estudo, eram montados os grupos experimentais e agendadas as sessões, cada uma com cinco participantes. Imediatamente antes da sessão, era realizado o sorteio de qual seria o audiovisual apresentado ao grupo.

\section{Execução das sessões experimentais.}

As 16 sessões experimentais ocorreram nas dependências da UFSC. Todas foram gravadas em áudio e vídeo. Durante as sessões os participantes eram recebidos no local e esclarecidos sobre a pesquisa, inclusive sobre a filmagem do encontro. Em seguida, para proporcionar um "aquecimento" ao grupo, os membros se apresentavam brevemente. A partir de então, o grupo assistia ao audiovisual (para metade dos grupos apresentou-se o audiovisual da saúde e para a outra parte apresentou-se o da beleza). Em seguida, iniciava-se uma conversa em grupo sobre o tema "corpo", utilizando-se a técnica do grupo focal. As discussões em grupo focal representam o modo como as opiniões são geradas, expressadas e modificadas na vida cotidiana (Flick, 2004). Esta atividade durava entre 20 e 40 minutos, e favoreceu a emergência das representações e dos valores vigentes no grupo em relação à temática "corpo". A última atividade consistia em responder ao questionário e ao fim, eram entregues os termos de consentimento livre e esclarecido e propunha-se um momento de dessensibilização aos participantes. Antes de iniciar a coleta de dados, realizou-se um estudo piloto por meio da aplicação dos instrumentos e procedimentos em três grupos, com objetivo de avaliar a adequação do procedimento previsto e dos instrumentos utilizados, bem como realizar o treinamento da experimentadora.

Em conformidade com as normas 196/96 do Conselho Nacional de Saúde, o projeto foi encaminhado para o Comitê de Ética em Pesquisa com Seres Humanos (CEPSH) da UFSC e foi avaliado quanto à adequação de aspectos éticos de pesquisa, tendo obtido parecer favorável ao processo 216/09. Todos os procedimentos éticos foram considerados; os participantes foram voluntários e tiveram acesso aos resultados. 


\section{Análise de Dados}

O material verbal referente aos grupos focais foi transcrito integralmente e separado em áreas temáticas: o que é o corpo; partes do vídeo que chamaram atenção; o corpo no dia-a-dia, sendo que apenas a primeira área temática foi analisada no estudo. Os dados do questionário foram tabulados em planilhas por meio do software SPSS 17.0, onde as mesmas foram analisadas por estatística descritiva e relacional.

$\mathrm{O}$ material referente às transcrições dos grupos focais foi submetido a uma Classificação Hierárquica Descendente (CHD), realizada pelo programa ALCESTE (Reinert, 1998). Nesse tipo de análise, o texto é segmentado em pedaços de tamanho semelhante (Unidades de Contexto Elementar UCE) e esses segmentos de texto são classificados em função dos seus respectivos vocabulários, sendo que o conjunto deles é repartido em função da frequência das palavras reduzidas aos seus radicais. A partir de matrizes cruzando segmentos de textos e palavras (em repetidos testes do tipo $\chi^{2}$ ), aplica-se o método de CHD e obtém-se uma classificação estável e definitiva (Reinert,1990). A CHD indica contextos lexicais, associados ou não a variáveis descritivas dos participantes, que, de acordo com Veloz, Nascimento-Schulze e Camargo (1999), podem ser considerados como aspectos de uma RS ou RS distintas.

As evocações livres foram submetidas a uma Análise Fatorial de Correspondência (AFC), que consiste em um método estatístico multivariado, o qual permite a identificação de diferentes fatores, ou seja, diferentes dimensões da relação entre o material textual e as variáveis descritivas dos participantes (Lorenzi-Cioldi, 1983). Essa análise foi processada com auxílio do programa informático SPAD (Lebart \& Salem, 1988) partir de uma tabela lexical de contingência que considerou os participantes em linha e as palavras evocadas em coluna.

As variáveis independentes, ou explicativas, não entraram no cálculo de associações, mas foram consideradas como ilustrativas e projetadas no plano fatorial. Segundo Le Roux e Rouanet (2009), quando objetiva-se verificar o efeito de variáveis controladas, que não se correlacionam entre si, estas não devem entrar na construção da tabela de contingência. Assim, a AFC é capaz de explicar a dispersão total dos dados a partir da relação entre os indivíduos e as palavras, de modo que as variáveis de controle são associadas a posteriori. Tal tipo de análise permite uma maior fidedignidade na interpretação dos resultados de um estudo de delineamento experimental.

\section{Resultados}

Observou-se que a maioria dos participantes $(N=55)$, encontra-se no peso considerado saudável pela WHO e 18 deles encontram-se acima do peso. Quando comparados os grupos geracionais, observa-se diferença significativa entre jovens e adultos em relação ao IMC, sendo que apenas dois jovens estavam com sobrepeso, enquanto entre os adultos, a frequência foi de $16\left[\chi^{2}(2, N=79)=18,3 ; p<0,001 ; V C=0,5\right]$.

Em relação à satisfação corporal, 50 participantes declararam-se satisfeitos, enquanto 15 declararam insatisfação. Não houve diferença significativa entre homens e mulheres, mas sim entre os grupos geracionais. Verificou-se que o grupo de adultos declarou maior satisfação corporal, sendo que 30 relataram estar satisfeitos. Entre os jovens, 20 declararam-se satisfeitos $\left[\chi^{2}(4, N=0)=17,6 ; p<0,005 ; V C=0,5\right]$. Observa-se uma inconsistência entre IMC e satisfação corporal: grande parte dos participantes adultos $(N=16)$ encontra-se acima do peso, e a maioria deles declarou-se satisfeita; enquanto entre os jovens ocorre o fenômeno inverso, IMC saudável à maioria e satisfação apenas para a metade dos participantes.

Verificou-se a atitude dos participantes em relação ao corpo por meio de uma tarefa onde os mesmos comparavam a importância que atribuíam ao corpo, à profissão e à tradição familiar em sua vida, a partir da atribuição de uma pontuação. A média geral de pontos atribuídos ao corpo foi de 4,11 $(D P=1,30)$, enquanto a média de pontos atribuídos à profissão foi 3,09 $(D P=1,09)$ e para a tradição familiar foi $2,77(D P=1,2)$. Pode-se constatar que a maioria dos participantes atribui importância maior ao corpo do que aos demais aspectos citados.

\section{Representações Sociais sobre o Corpo}

O conteúdo das representações sociais sobre o corpo foi coletado de duas formas, sendo uma coletiva (grupo focal) e a outra individual (teste de evocações livres). Este material foi analisado separadamente e ambos serão descritos a seguir.

\section{Representações sociais emergentes a partir da técnica do grupo focal.}

A partir das transcrições do material dos grupos-focais elaborou-se um corpus denominado "Corpo". Este foi submetido a uma CHD e era composto por 16 Unidades de Contexto Iniciais (UCI), as quais se desdobraram em 778 Unidades de Contexto Elementares (UCE). Destas, $82 \%$ foram retidas na CHD, representada na Figura 1.

Na primeira partição do corpus, a classe 3 (27\%), diferenciou-se do restante do material textual. Na segunda partição, as classes $1(54 \%)$ e $2(19 \%)$ diferenciaram-se entre si, de modo que a CHD distinguiu três classes. Foram consideradas na análise as palavras com frequência maior que três, e dentre as analisadas obteve-se frequência média de 14,95. O dendograma da Figura 1 apresenta as palavras com frequência total superior à média e $\mathrm{x}^{2}$ superior a 3,84 $(g l=1 ; p<0,05)$. Na Figura 1 podem ser observadas para cada classe: as palavras significativas, a frequência de cada palavra na classe e o $\mathrm{x}^{2}$ das mesmas na classe.

A classe $3(27 \%)$ está associada aos participantes adultos $\left(\mathrm{x}^{2}=66\right)$, aos homens $\left(\mathrm{x}^{2}=42\right)$ e ao contexto saúde $\left(\mathrm{x}^{2}=12\right)$. $\mathrm{O}$ conteúdo refere-se a uma relativização da importância dos cuidados com o corpo e aponta para uma negação do corpo. Apresentam-se ideias relacionadas ao cotidiano, o qual necessita do convívio social agradável, de modo que o bem-estar social é considerado mais importante do que os cuidados com o corpo e sua saúde. Um exemplo deste tipo de representação pode ser ilustrado pelo trecho a seguir: "Não adianta ter um corpo saudável se teu momento de lazer, familiar, o teu dia a dia, não te der essa oportunidade". 


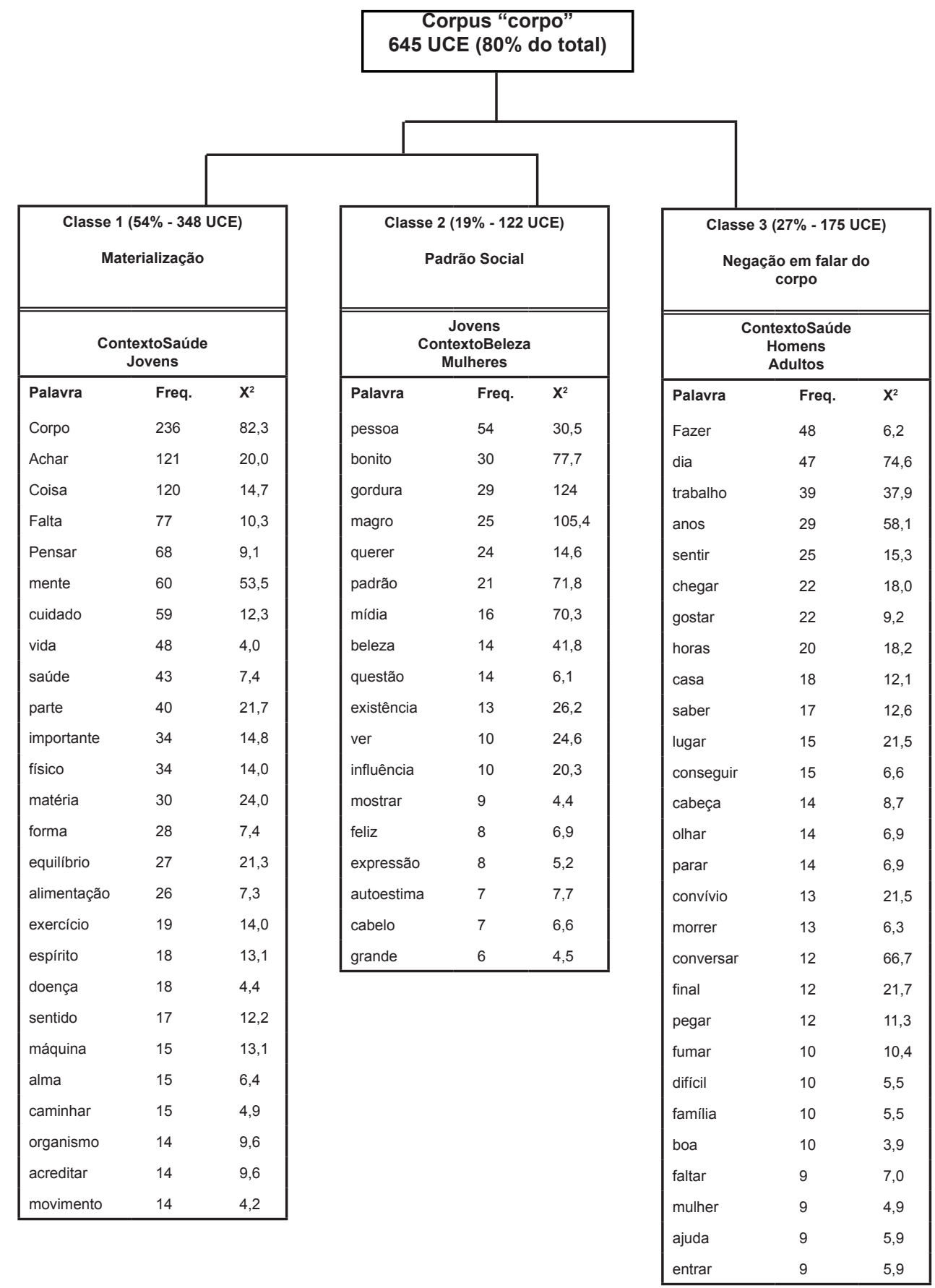

Figura 1. Dendograma da CHD do corpus "Corpo".

Por outro lado, a classe também contém ideias referentes à rotina de trabalho, a qual impossibilita que as pessoas estejam atentas ao próprio corpo, como se observa no excerto "Mas a gente não presta atenção. Ontem a gente fez um trabalho até quatro horas da manhã e acordamos às seis horas, dormimos duas horas. A gente repara no dia a dia que fica mal humorado, sente mal, não está bem, não está descansando direito".

O outro grupo de UCE, que compõe as classes 1 e 2, trata mais especificamente do corpo. No entanto, este grupo apresenta distinções marcantes, que se mostram na segunda partição. A classe 1, a qual abrange o maior número de UCE, está associada ao contexto de saúde $\left(\mathrm{x}^{2}=30\right)$ e aos participantes jovens $\left(x^{2}=12\right)$. Esta classe representa o corpo enquanto materialização e considera uma integração entre a mente a o corpo, o que pode ser exemplificado pelo trecho: "Eu acho que é isso tudo mesmo, é matéria, é o corpo. O espirito está no corpo, está tudo dentro de uma coisa só, que é isso aqui tudo, que é o meu eu, sou eu, o meu corpo para eu poder me movimentar". Ou seja, essa classe traz o corpo como a concretização da vida, portanto a saúde do corpo deve ser cuidada, especialmente por meio de exercícios e alimenta- 
ção, possibilitando um equilíbrio entre funções orgânicas e aspectos subjetivos ou espirituais.

Por fim, a classe 2, associada ao contexto de beleza $\left(x^{2}=118\right)$, às mulheres $\left(x^{2}=42\right)$ e aos jovens $\left(x^{2}=24\right)$ evidencia a importância dos padrões sociais em relação ao corpo, os quais são amplamente divulgados pela mídia e na atividade de grupo focal foram criticados ou questionados pelos participantes, e ilustra-se claramente as normas sociais em relação à aparência do corpo. Observa-se que tais normas poucas vezes são declaradamente assumidas pelos participantes, de modo que se fala dessas exigências em relação à aparência sempre na esfera coletiva, da sociedade em geral, e associado ao consumo. Os participantes evidenciam que individualmente não consideram adequada a norma social vigente, como no excerto: "E o gordo é bonito, às vezes é muito mais bonito que uma pessoa muito magra, que está magra, mas que não esteja bem com ela mesma...A pessoa gorda, mas que se veste bem, fica bonita, porque ela se aceita. Diferente do que o padrão de beleza impõe, e um padrão de beleza consumista, tem que usar aquela roupa, tem que ter aquele cabelo, tem que estar magrinha".

\section{Representações sociais emergentes a partir do teste de evocações livres.}

Uma AFC foi realizada, na qual o $\mathrm{phi}^{2}$ total foi 13 e foram necessários 52 fatores para explicar $100 \%$ da inércia total. Esse alto número de fatores explica-se pelo fato da tabela de contingência ter sido construída a partir do cruzamento entre os participantes $(N=79)$ e as palavras $(N=56)$. Considerando-se que os primeiros fatores são aqueles que explicam os aspectos mais compartilhados da dispersão total dos dados, utilizando-se a técnica do screeplot para a extração de fatores (Cattell, 1966), será focalizada no presente estudo a descrição dos quatro primeiros fatores.
Cada um dos fatores considerados nesta análise explica cerca de $5 \%$ da inércia (Fator 1- 5,11\%; Fator 2- 4,84\%; Fator 3-4,65\%; Fator 4- 4,45\%) de modo que a dispersão explicada pelos quatro fatores é próxima de $20 \%$ do total. Considerou-se como integrantes representativos de um fator os elementos com contribuição igual ou maior a dois. As variáveis de delineamento, consideradas ilustrativas nessa análise, não possuem valor de contribuição, mas considerou-se que as mesmas seriam importante ao fator quando o valeur-test é maior ou igual a dois (Lebart, Morineau \& Piron 2000). A Figura 2 ilustra a representação gráfica dos fatores 1 e 2, com $10 \%$ da inércia total, explicando efeitos ligados ao contexto e ao grupo geracional.

O fator 1 opõe uma representação de corpo ligada à materialização do mesmo, à noção de vida e equilíbrio entre mente e corpo; com uma representação ligada à aparência e beleza do corpo, sua expressividade e sexualidade. A primeira representação associa-se ao contexto saúde e aos adultos; enquanto a segunda está associada ao contexto de beleza e aos jovens. A relação das variáveis contexto e grupo geracional, permite observarmos uma proximidade entre os jovens e os adultos no contexto se saúde (JS e AS), em oposição aos jovens no contexto de beleza (JB).

O fator 2 caracteriza as evocações dos jovens, apontando aspectos corporais ligados à existência e à identidade, dentro de um convívio social, além de mencionar o elemento cuidado, o qual provavelmente diz respeito ao cuidado com a aparência. Trata-se de uma representação de caráter subjetivo, e ao mesmo tempo pragmática no que se refere aos modos de interação social, que está em contraposição ao corpo enquanto matéria, vinculado aos adultos. Especificamente, a partir da relação entre contexto e grupo geracional, verifica-se que a representação dos jovens trata-se mais especificamente daquela ativada no contexto beleza.

A sobreposição dos fatores 1 e 2 implica na constatação de duas dimensões das representações sociais sobre o corpo

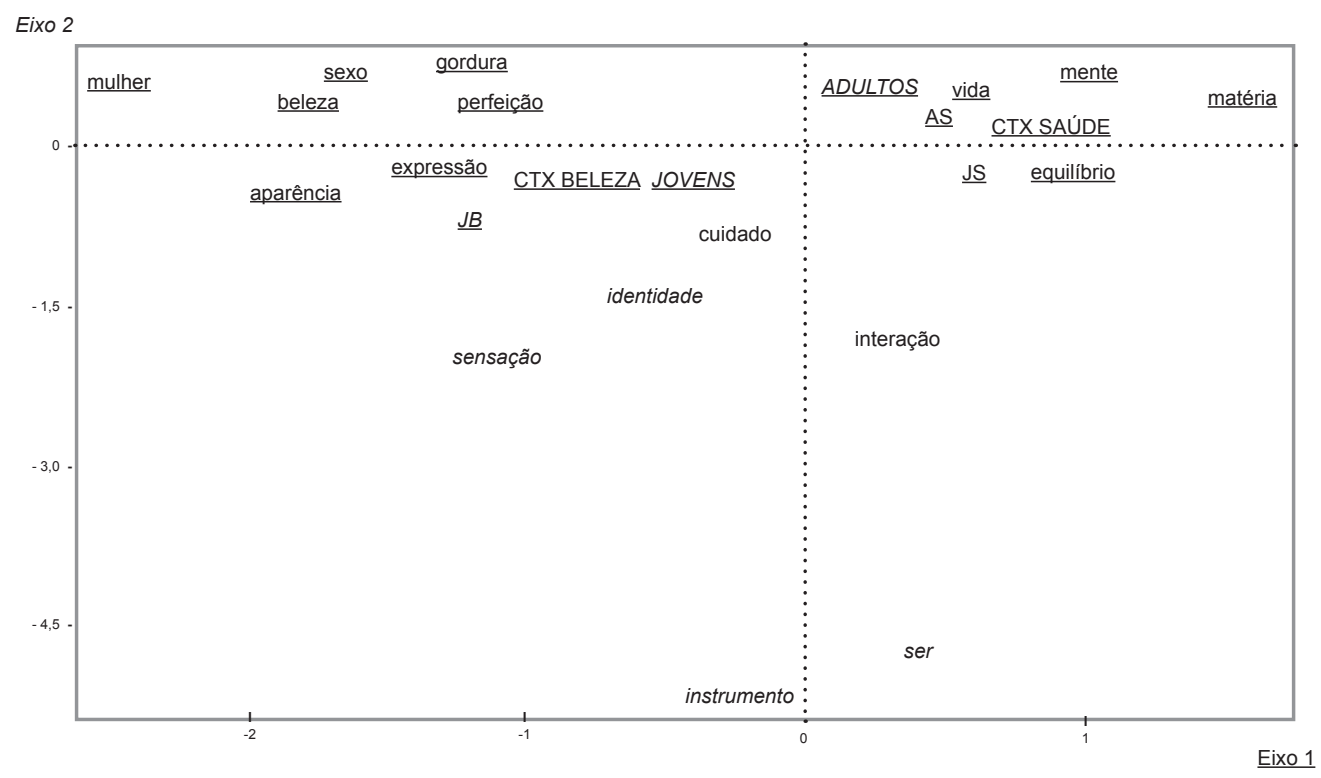

Figura 2. Representação gráfica dos planos fatoriais 1 (sublinhado) e 2 (itálico). 


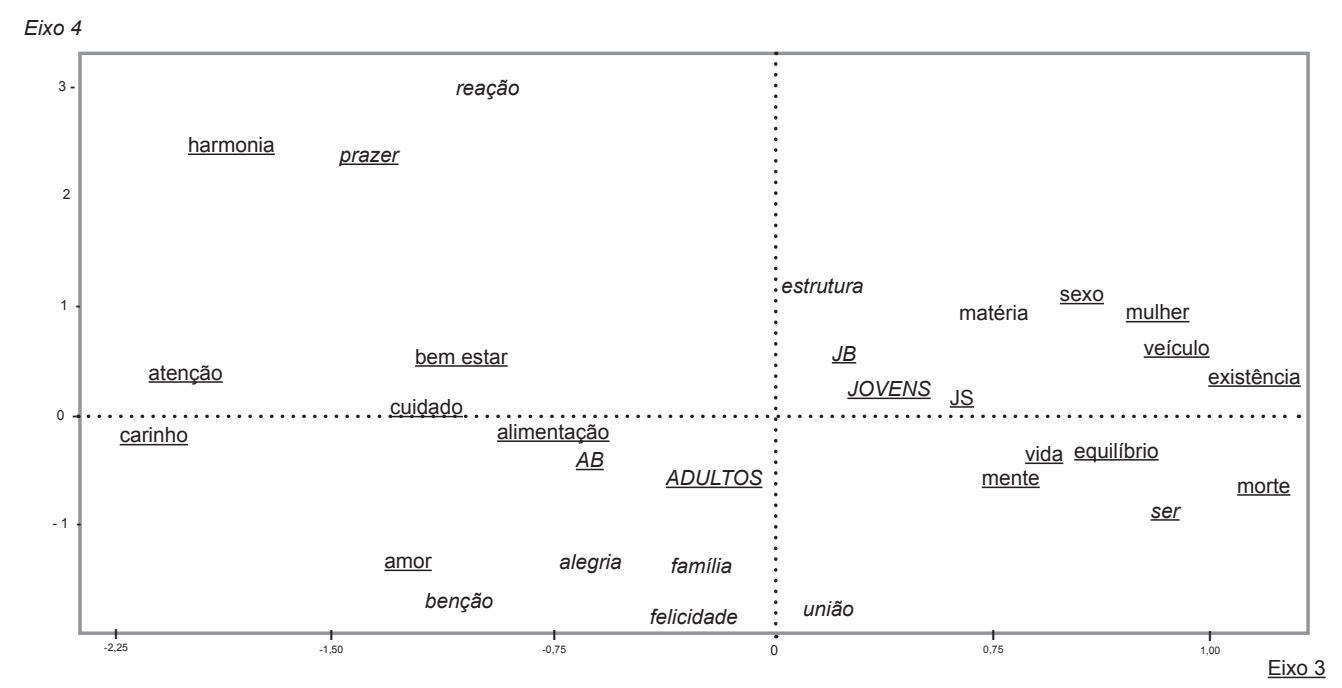

Figura 3. Representação gráfica dos planos fatoriais 3 (sublinhado) e 4 (itálico).

evocadas no contexto de beleza pelos participantes jovens: uma (fator 1) mais objetiva e voltada para a beleza do corpo, e a segunda com elementos mais abstratos mas que falam do caráter instrumental e ao mesmo tempo, individual do corpo. Ressalta-se, que o primeiro fator numa AFC revela sempre os elementos mais estereotipados da RS enquanto os demais fatores apresentam outras dimensões menos representativas, mas de considerável importância.

Os fatores 3 e 4 explicam, considerando-se as variáveis isoladamente, as diferenças geracionais. No entanto, ao considerar-se a relação entre as variáveis: contexto e geração podem-se constatar especificidades. O plano fatorial encontra-se representado na Figura 3.

O fator 3 opõe os jovens e os adultos; mais especificamente, os jovens no contexto saúde e os adultos no contexto beleza. Os jovens trazem elementos relacionados à noção de existência (vida e morte), equilíbrio entre mente e corpo já observada em outros fatores. No entanto, aqui a sexualidade (mulher e sexo) apresenta-se associada ao contexto de saúde. Por outro lado, os adultos apresentam em relação ao contexto de beleza ideias que pouco expressam normas estéticas, mas sim elementos subjetivos ligados a sensações ou sentimentos agradáveis, além dos elementos pragmáticos: "cuidado e alimentação".

Por fim, o fator 4 evidencia uma oposição entre jovens e adultos, ambos os grupos no contexto beleza, na qual os jovens evocaram elementos ligados à materialidade do corpo, ao prazer e harmonia; enquanto os adultos trazem uma representação similar à apresentada no fator 3 , com elementos subjetivos ligados ao bem-estar, junto com "exercício" de caráter mais pragmático.

\section{Discussão}

Destaca-se a importância do estudo do corpo com base na TRS, que contribui com a compreensão do corpo auxiliando a esclarecer o papel do conhecimento compartilhado na sua valorização (Jodelet, 1994) e na importância da beleza e da saúde e suas consequências para as pessoas. Procurou-se identificar, a partir de um estudo quase-experimental, de que forma os contextos de saúde e de beleza interferem na ativação das RS sobre o corpo.

O grupo-focal realizado após a apresentação do audiovisual possibilitou que se verificasse o conteúdo da RS num ambiente semelhante àqueles em que as opiniões são geradas, expressas e modificadas no dia-a-dia (Flick, 2004). A CHD referente ao corpus "Corpo" evidenciou três contextos lexicais (Nascimento-Schulze \& Camargo, 2000), sendo que um deles refere-se ao "não falar" sobre o corpo. Acerca desse conteúdo lexical, observou-se uma negação do corpo e da sua consideração no cotidiano das pessoas. Pode-se falar de um efeito de mascaramento da RS (Flament, Guimelli, \& Abric, 2006), que ocorre em virtude do contexto normativo, também denominada mudas das RS. A zona muda seria uma parte da RS que pertence à consciência e é reconhecida pelos indivíduos, entretanto não pode ser expressa, uma vez que é composta por elementos contra normativos. Indica possivelmente um posicionamento velado e é determinada essencialmente pela situação social na qual a RS é produzida (Abric, 2005). Assim, a respeito do não falar sobre o corpo, mas de outros assuntos, pode-se mencionar o fenômeno do mascaramento da RS sobre o corpo ocorrido entre os participantes, na medida em que alguns aspectos da RS podem não ter emergido claramente durante a coleta dos dados. Salienta-se que os participantes do estudo compartilhavam o ambiente universitário, onde o intelecto é priorizado em detrimento do corpo; prioridade esta que se evidenciou nas discussões nos grupos-focais.

Por outro lado, aquele conteúdo que se referiu diretamente ao corpo, apresentou duas RS distintas. A mais compartilhada refere-se à materialidade do corpo, enquanto um objeto que é capaz de integrar a parte subjetiva com a parte orgânica, considerando os cuidados que se deve ter com ambas. A RS com menor grau de compartilhamento, por sua vez, refere-se ao corpo enquanto um objeto social, da beleza e dos padrões sociais, impostos pela mídia e questionados pelos participantes no grupo-focal.

O corpo reúne ao mesmo tempo características biológicas e psicológicas, individuais e sociais; sendo simbolizado de 
acordo com uma interação destes fatores (Andrieu, 2006), visão esta que também se mostra na RS dos participantes do estudo. Foram evidenciados nos grupos-focais e nas evocações conteúdos que se referem ao caráter orgânico do corpo, ao seu caráter psicológico/mental, e a sua importância social.

A respeito dos estudos de RS, Wagner (1998) propõe dois níveis de avaliação fundamentais na pesquisa: o nível individual e o nível social. Neste estudo, ao utilizar a técnica de grupo-focal, somada à aplicação de questionários, pode-se contemplar ambos os níveis de análise propostos por Wagner. $\mathrm{O}$ material recolhido a partir dos grupos-focais forneceu $\mathrm{o}$ conteúdo das RS sobre o corpo disponível em nível social: o corpo enquanto matéria orgânica, que operacionaliza a vida; os padrões sociais de beleza, os quais foram questionados; e uma negação do corpo. O nível individual de análise, todavia, trouxe informações complementares acerca do pensamento social sobre o corpo, as quais provavelmente não apareceriam num nível social, por pressões normativas presentes em uma atividade em grupo. São exemplos destas: a insatisfação dos jovens com o seu corpo, atitude em relação ao corpo e alguns elementos da RS de caráter mais íntimo como sexualidade e sensorialidade, dentre outros. Tal constatação vai ao encontro do que propôs Almeida (2009), a qual chama atenção para a possibilidade dos estudos de RS conectarem o individual ao coletivo, evidenciando que os processos para funcionar em sociedade são orientados por dinâmicas sociais, de forma que nem todos estes podem ser explicitados em todas as situações.

Conforme aponta Wagner (1998), as RS sobre um objeto variam de acordo com o grupo social e sua implicação em relação ao objeto representado. Os resultados desta pesquisa, confirmando a hipótese principal, apontam que membros de uma mesma cultura ou grupo social, numa mesma etapa de vida e com graus de implicação semelhantes; representam o corpo de formas diferentes em função do contexto imediato (Abric \& Gimelli, 1998) onde se dá a interação que demanda a emergência de tais RS. A interferência do contexto de inserção (saúde ou beleza) na ativação das RS sobre o corpo para os participantes do estudo foi verificada tanto nos grupos-focais quanto no teste de evocações livres. Destaca-se que também foram observadas diferenças no âmbito das RS do corpo entre sexo e geração.

O material textual produzido pelos grupos-focais no contexto de saúde foi mais volumoso e mais rico, em termos de quantidade de elementos associados exclusivamente a este contexto. No que diz respeito aos significados compartilhados no contexto saúde, pode-se observar (Figura 1) que os grupos expressam o caráter orgânico e funcional do corpo, e práticas ligadas à saúde. Nesse contexto o corpo está relacionado com a vivência espiritual, ou psicológica, de modo que o corpo físico é instrumento o que viabiliza e ao mesmo tempo abriga estas experiências. No contexto beleza, por sua vez, aparecem algumas ideias acerca do corpo orgânico, matéria viva, que reflete a energia do indivíduo, no entanto evidenciam-se elementos concretos, que representam um corpo normatizado, subordinado aos padrões de beleza e aos desvios destes padrões. Verifica-se, no entanto, que o discurso dos participantes trata-se menos da referência à adesão às normas e mais de uma reflexão crítica em relação a estas. Nesse contexto, alguns participantes consideram a autoestima como um aspecto fundamental, capaz de levar as pessoas a superarem a importância social dos padrões de beleza, os quais podem ser relativizados.

Considera-se que a ideia de contexto aqui empregada é equivalente ao conceito de metassistema, proposto por Doise (2011). O metassistema constitui-se de regulações sociais normativas que controlam as operações cognitivas, sendo que, de acordo com a ocasião, os indivíduos podem fazer intervir diferentes metassistemas. As questões ligadas à saúde do corpo e seu caráter orgânico aparecem em ambos os contextos, embora sejam mais características no contexto saúde. Por outro lado, as noções de beleza e padrão social que emergem no contexto beleza são praticamente inexistentes no contexto saúde.

Rodrigues, Assmar \& Jablonski (2009), ao se referirem à beleza nas relações interpessoais, apontam que esta parece ser avaliada de forma contraditória em nossa sociedade. Se por um lado proliferam-se as cirurgias plásticas, academias de ginástica e clínicas estéticas, por outro, existe uma norma implícita na qual a valorização da beleza é considerada fútil e superficial, sendo outras características das pessoas mais importantes de serem valorizadas. Assim, constata-se que em nossa sociedade a beleza é valorizada, mas geralmente de uma forma velada e silenciosa. Verificou-se nos grupos-focais indícios desta contradição. Observou-se que mesmo quando o contexto da interação favorece ao grupo falar sobre a beleza, minimizando as pressões normativas que poderiam existir no contexto institucional de uma universidade, ainda fala-se sobre a busca pela beleza na terceira pessoa.

AAFC realizada a partir das evocações livres tornou evidente as diferenças das RS emergentes nos distintos contextos e apresentou ainda a interação entre as variáveis contexto e geração, indicando que as implicações do contexto foram diferentes entre os jovens e os adultos.

A Figura 4 sintetiza que a principal distinção entre os dois contextos reside no papel que é atribuído ao corpo. No contexto saúde o corpo é pensado a partir da individualidade,em termos de cuidados com a saúde de um corpo orgânico, veículo da vida e que necessita de equilíbrio. Tal representação é semelhante a uma dimensão da RS da saúde encontrada por Galand e Salès-Wuillemin (2009). No contexto beleza, a ideia de corpo está ancorada na interação do indivíduo com o mundo; na forma como ele se apresenta aos demais, naquilo que ele pode adquirir do mundo a partir do seu corpo. Ambas as representações mesclam-se em elementos concretos e abstratos, embora a segunda contemple normas sociais mais definidas.

Estas duas dimensões da RS sobre o corpo já haviam sido identificadas inicialmente por Jodelet et al. (1982). Trata-se de duas representações compartilhadas sobre o corpo, e que tendem a ser perenes. Porém, a manipulação realizada no presente estudo permitiu verificar que tais dimensões são ou não ativadas nas RS, em função do contexto em que a interação social ocorre.Salienta-se que a manipulação experimental não apresentou apenas um efeito no que se refere à ativação dos elementos periféricos da RS, conforme apontam Abric e Guimelli (1998) quando os mesmos mencionam as decorrências do contexto imediato na emergência das RS. Conforme ilustra a Figura 4, pode-se observar que o único elemento compartilhado nos dois contextos é o elemento saúde, o qual adquire sentidos distintos quando associado 


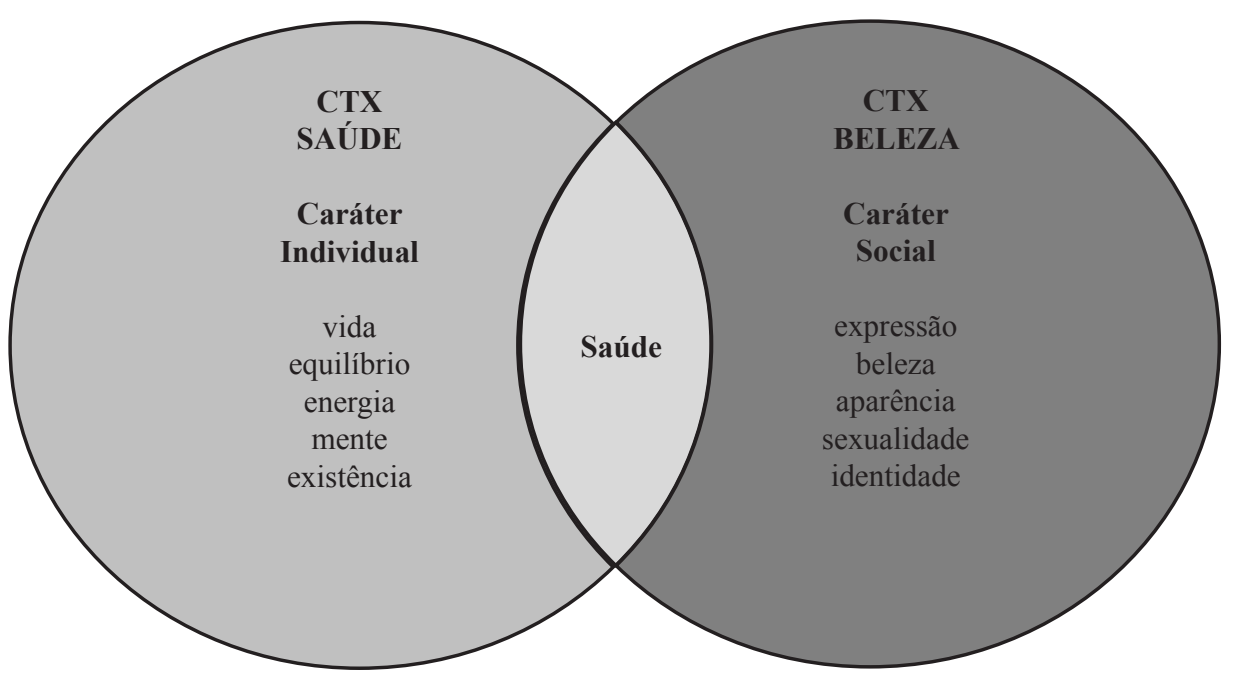

Figura 4. Síntese da RS sobre o corpo em relação aos contextos de inserção saúde e beleza.

aos demais elementos, conforme o contexto em que se insere. Constata-se, portanto, que em função do contexto emergem duas RS sociais de corpo distintas, o que aponta para algumas considerações.

As constatações acerca das implicações do contexto de inserção do objeto corpo nas RS apontam para importantes decorrências metodológicas: a complexidade e as minúcias a serem avaliadas nos estudos de RS. Autores já apontavam (Abric \& Guimelli 1998; Flament \& Rouquette, 2003; Wachelke, 2007), e os resultados desta pesquisa reiteram que ao diagnosticar as RS de uma população sobre determinado objeto é importante considerar qual o contexto em que as informações são recolhidas e quais as circunstâncias em que as RS são utilizadas no cotidiano, os quais nem sempre são equivalentes. Segundo Wachelke (2007), as RS são fenômenos difíceis de ser captados empiricamente e alguns aspectos da coleta de dados podem ocasionar interferências a serem consideradas nos resultados dos estudos.

Desde o estudo fundador da TRS, conhece-se que qualquer RS é sempre de alguma coisa (objeto da representação) e de alguém (sujeito) (Moscovici, 1961), de modo que as características de ambos se manifestam na representação (Jodelet, 2001). Entretanto, ao avaliar as implicações do contexto de inserção, verifica-se que além de requerer um sujeito e de um objeto, a RS só pode se manifestar a partir algum contexto imediato de interação social, o qual repercute diretamente no conteúdo que é manifesto. Toda a RS tem um objetivo prático (Abric, 1998; Jodelet, 2001) e essa prática ocorre em determinada situação específica, que atualiza a RS, garantindo seu caráter dinâmico, o que implica em considerar que são diferentes as RS utilizadas em situações cotidianas, onde o foco é a saúde ou a estética corporal e, consequentemente, as atitudes e comportamentos também seriam distintos. Se tal fenômeno foi verificado em relação ao corpo, possivelmente poderá ser verificado em relação a outros objetos de estudo.

No que se refere às diferenças geracionais, verificou-se que embora em grande parte as RS de jovens e adultos tenham sido compartilhadas, particularidades na forma com que os grupos expressaram seus pensamentos acerca do corpo foram constatadas, o que pode ser justificado pelo fato de que para os jovens o corpo é um objeto de maior importância social, em virtude da etapa do desenvolvimento que os mesmos vivenciam, interferindo consideravelmente nas suas interações sociais (Camargo, Justo, \& Jodelet, 2010). Sendo um objeto de maior relevância social, há mais disponibilidade dos jovens para conversar sobre este assunto. Para os adultos na faixa dos 50 anos, por outro lado, a importância social do corpo é diminuída. Este grupo de pessoas usualmente já possui redes sociais consolidadas, e o corpo adquire menor importância na mediação das relações sociais. Além disso, a vivência do processo de envelhecimento pelos adultos é caracterizada por um declínio das funções orgânicas (Papaleo-Netto, 2002), quando usualmente destacam-se as limitações e as perdas, e não o processo de desenvolvimento (Papaléo-Netto, 2002). Tais alterações metabólicas, com repercussões sociais, pode repercutir na forma como os adultos se expressam a respeito do corpo.

Verificou-se que a saúde é o eixo estruturante da RS. Para os participantes do estudo parece ser difícil pensar em corpo sem pensar na saúde do corpo. No entanto, ficou evidente que a saúde, ao se associar com os demais elementos representacionais, reflete duas noções diferentes de corpo em função do contexto em que o corpo está inserido. Trata-se do corpo que é o veículo da vida humana, o corpo que tem energia, que adoece, que vai ao médico, e que precisa de equilíbrio? Ou trata-se do corpo como objeto social, que permite que os indivíduos interajam com o mundo, se expressem, comuniquem-se com os demais, seduzam; o corpo que é influenciado pela mídia e pela sociedade impondo padrões estéticos? Para ambas as gerações participantes da pesquisa essas duas RS estão presentes e se manifestam em função do estímulo social que se apresenta. Assim, não se trata de uma RS de corpo, mas diferentes RS que seriam utilizadas conforme a demanda da situação imediata. Ou seja, quando falamos em RS acerca de um objeto, passamos a considerar, além da natureza do objeto e do grupo que o representa, também a condição onde essa RS é emergente e expressa. 


\section{Referências}

Abric, J. C. (1998). A abordagem estrutural das representações sociais. In A. S. P. Moreira \& D. C. de Oliveira (Eds.), Estudos interdisciplinares de representação social (pp. 27-38). Goiânia: $\mathrm{AB}$.

Abric, J. C. (2005). A zona muda das representações sociais. In D. C. d Oliveira \& P. H. F. Campos (Eds.), Representações sociais, uma teoria sem fronteiras (pp. 23-34). Rio de Janeiro: Museu da República.

Abric, J. C., \& Guimelli, C. (1998). Représentations sociales et effets de contexte. Connexions, 72, 23-37.

Almeida, A. M. O. (2009). Abordagem societal das representações sociais. Sociedade e estado, 24(3), 713-737. Retrieved from: http://www.scielo.br/pdf/se/v24n3/05.pdf.

Andrieu, B. (2006). Corps. In B. Andrieu (Ed.), Le dictionnaire du corps en sciences humaines e sociales (pp. 103-104). Paris: CNRS Editions.

Azevedo, R. C. S., \& Ramos, F. R. S. (2006). Modos de conhecer e intervir: a constituição do corpo no cuidado de enfermagem no hospital. Texto Contexto Enfermagem, 15(Esp), 55-63.

Bacon, E. E. (1986). Dicionário de Ciências Sociais. Rio de Janeiro: Editora da Fundação Getúlio Vargas.

Camargo, B. V.(2006). Relações de dependência entre representações sociais e efeitos do contexto interacional nas representações de um mesmo objeto. Projeto de pesquisa. Universidade Federal de Santa Catarina, Florianópolis, SC.

Camargo, B. V., Justo, A. M. \& Jodelet, D. (2010) Normas, Representações Sociais e Práticas Corporais. Revista Interamericana de Psicología, 44(3), 456-464.

Camargo, B. V., \& Justo, A. M. (2008). Representações sociais do corpo. Relátório de pesquisa não publicado - PIBIC UFSC/ CNPq, Florianópolis.

Camargo, B. V., Goetz, E. R., \& Barbará, A. (2005). Representação social da beleza de estudantes de moda. Textos Completos da IV Jornada Internacional e II Conferência Brasileira sobre Representações Sociais, 3353-3362.

Campbell, D. T. \& Stanley, J. C (1979). Delineamentos experimentais e quase-experimentais de pesquisa. São Paulo: EPU

Cattell, R. B. (1966). The screen test for the number of factors. Multivariate Behavioral Research, 1, 245-276.

Doise, W. (2011). Sistema e metasistema. In A. M. O. Almeida, M. F. S. Santos, \& Z. A. Trindade (Eds.), Teoria das representações sociais: 50 anos (pp. 123-156). Brasília; Techbopolitik.

Doise, W., Clemence, A., \& Lorenzi-Cioldi, F. (1992). Représentations sociales et analyses de données. Grenoble: PUF.

Durozoi, G. (1996). Dicionário de Filosofia. Campinas: Papirus.

Flament, C., \& Rouquette, M.-L. (2003). Anatomie des idées ordinaires. Paris: Armand Colin.

Flament, C., Guimelli, C., \& Abric, J. -L. (2006). Effets de masquagedansl'expression d'une représentation sociale. Cahiers Internationaux de Psychologie Sociale, 69, 15-31.

Flick, U. (2004). Uma introdução à pesquisa qualitativa. Porto Alegre: Bookman, 2004.

Galand, C., \& Salès-Wuillemin, E. (2009). Apports de l'étude des représentations sociales dans le domaine de la santé. Sociétés, 105(3), 35-44.
Gamboa, J. A. J., Tura, L. F. R., \& Bursztyn, I. (2009). Representações sociais do corpo em estudantes do ensino médio. Anais IV Conferência Brasileira sobre representações sociais (pp. 119-120). Rio de Janeiro: UERJ.

Goetz, E. R., Camargo, B. V., Bertoldo R. B., \& Justo, A. M. (2008). Representações sociais do corpo na mídia impressa. Psicologia e Sociedade, 20(2), 226-236.

Günther, H. (2011). Métodos de pesquisa em psicologia social. In C. V. Torres \& E. R. Neiva, (Eds.), Psicologia social: principais temas e vertentes (pp. 58-76). Porto Alegre: Artmed.

Hillesheim, B., Somavilla, V. C., Lara, L., \& Dhein, G. (2005). Prácticas de salud y construcción del cuerpo feminino. Diversitas: Perspectivas em Psicologia, 1(2), 174-182.

Hoga, L. A. K., \& Reberte, L. M. (2006). Técnicas corporais em Grupo de Gestantes: a experiência dos participantes. Revista Brasileira de Enfermagem, 59(3), 308-313.

Jodelet, D. (1984). The representation of the body and its transformations. In R. Farr \& S. Moscovici (Eds.), Social representations (pp. 211-238). Cambridge: Cambridge University Press.

Jodelet, D. (1994). Le corps, la personeetautrui. In S. Moscovici, (Ed.), Psychologie sociale dês relations à autrui (pp. 41-68). Paris: Nathan.

Jodelet, D. (2001). Representações sociais: Um domínio em expansão. L. Ulup, (Trans.). In D. Jodelet (Ed.), As representações sociais (pp.187-203). Rio de Janeiro: Eduerj.

Jodelet, D., Ohana, J., Bessis-Moñino, C., \& Dannenmuller, E. (1982). Systeme de representation du corps et groupes sociaux (relatório vol. 1) Laboratoire de Psychologie Sociale: E.H.E.S.S.

Justo, A. M., Camargo, B. V., Moreira, A. B., \& Goetz, E. R. (2009, novembro). Representações Sociais sobre o Corpo: um abordagem estrutural. VI Jornada Internacional de Representações Sociais, Buenos Aires.

Kerlinger, F. N. (1980). Metodologia da pesquisa em ciências sociais: Um tratamento conceitual. São Paulo: EPU: EDUSP.

Le Pape, Y. (2006). Beauté/Laideur. In B. Andrieu, (Ed.), Le dictionnaire du corps en sciences humaines e sociales (pp. 48-49). Paris: CNRS Editions.

Lebart, L., \& Salem, A. (1988). Analyse statistique des données textuelles. Paris: Dunod.

Lebart, L., Morineau, A., \& Piron, M. (2000). Statistique exploratoire multidimensionelle. Paris: Dunod.

LeRoux, B., \& Rouanet, H. (2009). Multiple Correspondence Analysis. Londres: SAGE.

Lorenzi-Cioldi, F. (1983). L'analysefactorielle des correspondances dans les sciences sociales. Revue Suisse de Sociologie, 2, 365-390.

Moscovici, S. (1976). La psychanalyse, son image et son public. Paris: PUF. (Trabalho original publicado em 1961)

Nascimento-Schulze, C. M., \& Camargo, B. V. (2000). Psicologia social, representações sociais e métodos. Temas em Psicologia da SBP, 8(3), 287-299.

Natansohn, L. G. (2005). O corpo feminino como objeto médico e "mediático". Revista de Estudos Feministas, 13(2), 287-304. 
Oliveira, D. C., Marques, S. C., Gomes, A. M. T., \& Teixeira, M. C. T. V. (2005). Análise das Evocações Livres : uma técnica de análise estrutural das representações sociais. In A. S. P. Moreira, B. V. Camargo, J. C. Jesuíno, \& S. M. Nóbrega (Eds.), Perspectivas teórico-metodológicas em representações sociais (pp. 576-603). João Pessoa : Editora Universitária UFPB.

Ory, P. (2006). Le corps ordinaire. In A. Corbain, J. J. Courtine, \& G. Vigarello (Eds.), Historie du corps: Les mutations $d u$ regard. Le XX ${ }^{\mathrm{a}}$ siècle (pp. 129-449). Paris: Éditions du Seuil.

Papaléo-Netto, M. (2002). Epidemiologia do envelhecimento. In M. Papaléo-Netto, (Ed.), Gerontologia: a velhice e o envelhecimento em visão globalizada (pp. 26-23). São Paulo: Atheneu, 2002.

Reinert, M. (1990). ALCESTE, une méthodologie d'analyse des données textuelles et une application: Aurélia de G. de Nerval. Bulletin de Méthodologie Sociologique, 26, 24-54.

Reinert, M. (1998). Alceste: Analyse de données textuelles. Manuel d'utilisteur. Toulouse: Image.

Richardson, R. J., Peres, J. A. S., Wanderley, J. C. V., Correia, L. M., \& Peres, M. H. M. (2008). Pesquisa social: métodos e técnicas. São Paulo: Editora Atlas.

Rodrigues, A., Assmar, E., \& Jablonski, B. (2009). Psicologia Social (27a ed.). Rio de Janeiro: Vozes.

Rouquette, M. -L. (1994). Sur la connaissance des masses: essai de psychologie politique. Paris: PUF.
Souza-Filho, E. A., \& Beldarrain-Durandegui, A. (2009). The Contextual Analysis in Social Representations of the Body Among Ethnic Groups in Rio de Janeiro, Brasil. Universitas Psychologica, 8(3), 771-783.

Vala, J. (2006). Representações sociais e a psicologia social do conhecimento cotidiano. In J. Vala \& M. B. Monteiro (Eds.), Psicologia social (pp. 457-502, $7^{\mathrm{a}}$ ed.). Lisboa: Calouste Gulbenkian.

Veloz, M. C. T., Nascimento-Schulze, C. M., \& Camargo, B. V. (1999). Representações sociais do envelhecimento. Psicologia Reflexão e Crítica, 12(2), 479-501.

Wachelke, J. F. R. (2007) Efeitos das instruções de questões abertas na ativação de elementos derepresentações sociais (Unpublished Master's thesis). Universidade Federal de Santa Catarina.

Wagner, W. (1998). Sócio-gênese e características das representações sociais. In A. S. P. Moreira \& D.C. de Oliveira, (Eds.), Estudos interdisciplinares de representação social (pp. 3-25). Goiânia: $\mathrm{AB}$.

Recebido em 01.06.2012

Primeira decisão editorial em 03.12.2013

Versão final em 19.12.2013

Aceito em 05.02.2014 